\title{
Uma Perspectiva Evolucionária da Economia Agrícola: o caso da produção ovina no Brasil e Uruguai
}

\author{
João Garibaldi Almeida Viana ${ }^{1}$ e Paulo Dabdab Waquil²
}

\begin{abstract}
Resumo: O objetivo do artigo é desenvolver conceitos institucionais e evolucionários a fim de subsidiar a análise de mercados agrícolas. A construção teórica e analítica foi aplicada no caso da evolução da ovinocultura para responder à questão: variáveis institucionais e evolucionárias são determinantes para o aumento da produção de ovinos no Brasil e no Uruguai? A hipótese da pesquisa reside na importância das variáveis institucionais e evolucionárias no processo produtivo, sendo decisivo o papel das regras informais e da dinâmica econômica para o desenvolvimento futuro da atividade. Os dados do caso empírico foram analisados por meio de testes de hipóteses paramétricos e análise de regressão logística. Os resultados encontrados demonstram que fatores institucionais foram determinantes, tanto na manutenção de ovinocultores após um processo de mudança estrutural, como na pretensão futura de aumento da produção ovina nas duas regiões estudadas, apontando um papel decisivo para as regras informais da sociedade (costumes, tradições etc.) e modos não econômicos de pensar na dinâmica econômica da atividade após períodos de desequilíbrios. A pesquisa demonstrou a possibilidade da aplicação de pressupostos econômicos evolucionários, buscando, além de compreender o fenômeno, estimular o fortalecimento desta aproximação teórico-empírica em diversos temas da área da economia agrícola.
\end{abstract}

Palavras-chaves: economia evolucionária, economia rural, mudança estrutural, ovinocultura.

\begin{abstract}
The objective of this article was to develop institutional and evolutionary concepts to subsidize the analysis of agricultural markets. The analytical and theoretical constructions were applied in the case of the evolution of sheep production to answer the question: institutional and evolutionary variables are determinant to increase the sheep raising in Brazil and Uruguay? The hypothesis of the research is the importance of institutional and evolutionary variables in the production process, with the decisive

1. Universidade Federal do Pampa. Professor Adjunto. E-mail: joaoviana@unipampa.edu.br

2. Universidade Federal do Rio Grande do Sul. Professor Associado. E-mail: waquil@ufrgs.br
\end{abstract}


role of informal rules and economic dynamics for the future development of the activity. The data of empirical case were analyzed using parametric hypothesis tests and logistic regression analysis. The results show that institutional factors were decisive in both the maintenance of sheep farmers after a process of structural change, which has a future pretension of increasing sheep production in the two studied regions, indicating a decisive role in informal rules of society (customs, traditions etc.) and non-economic ways of thinking in the dynamics of economic activity after periods of imbalances. The research demonstrated the possibility of applying evolutionary economic assumptions, seeking to understand the phenomenon as well as stimulating the strengthening of this approach in several theoretical and empirical issues in the field of agricultural economics.

Key-words: evolutionary economics, agricultural economics, structural change, sheep production.

Classificação JEL: B52, Q13.

\section{Introdução}

A economia agrícola é um ramo da economia que investiga relações de causa e efeito, utilizando o método científico e a teoria econômica para encontrar respostas para os problemas dos mercados agroalimentares (CRAMER et al., 1997). No entanto, esta área de pesquisa tem mantido certo conservadorismo em relação aos seus pressupostos de análise e, embora a agricultura seja um setor em transformações contínuas, a literatura especializada mantém relação estreita com a economia neoclássica e seus pressupostos "imutáveis".

A emergência da teoria neoclássica como parte do mainstream econômico consolidou pressupostos e métodos para a compreensão econômica da dinâmica agrícola a partir do final do século XIX, e o setor agrícola começou a ser analisado a partir de instrumentos estáticos de oferta e demanda, funções de rendimentos decrescentes, equações de maximização de lucros e otimização da utilização de recursos. Ao longo do tempo, adicionaram-se à análise agrícola pressupostos neoclássicos como racionalidade ilimitada, fluxo de informações simétricas, equilíbrio e mercados competitivos.

Durante o século XX, a agricultura sofreu intenso processo de transformação, modificando tanto a estrutura produtiva do setor como os indivíduos responsáveis pelo desenvolvimento agrícola. Apesar de estas transformações terem originado uma nova dinâmica nos mercados alimentares, muito diferente da encontrada no fim do século XIX, os instrumentos dominantes de análise da economia agrícola permaneceram praticamente inalterados.

A industrialização da agricultura e suas consequências econômico-sociais trouxeram novas características aos mercados agrícolas, antagônicas aos pressupostos da economia neoclássica, como: comportamento dinâmico, existência de desequilíbrios, choques e instabilidades, assimetria de informações nos mercados, produções voltadas à tradição, cultura e sustentabilidade, a "busca" pelo lucro, a racionalidade limitada dos indivíduos, o intenso processo de inovação agroindustrial, as economias de escala e escopo, estruturas de mercado oligopolizadas, novos arranjos de comercialização, o aprendizado, os benefícios da interação dos indivíduos e a permanente influência de instituições.

Algumas transformações do ambiente agrícola estimularam a aplicação de conceitos heterodoxos, como no caso do papel das instituições e das estruturas de governança na coordenação das cadeias agroindustriais, baseados no arcabouço teórico da Nova Economia Institucional. Alguns instrumentos de base neoclássica, como estimação de curvas de oferta e demanda, elasticidades, análises de transmissão de preços e construção de cenários continuam sendo elementos relevantes 
para o estudo da economia agrícola. Entretanto, devem ser conciliados com uma análise sistêmica e flexível, compatível à realidade rural.

Assim, prevalece a carência de pesquisas que visem avaliar a evolução da dinâmica dos mercados agrícolas a partir de pressupostos institucionais e evolucionários, e com base na análise de mudanças conjunturais e estruturais, de desequilíbrios, de comportamentos individuais não otimizadores, da variabilidade de hábitos e costumes e da compreensão da história como fator fundamental para entender o presente e projetar o futuro.

A ovinocultura se destaca por ser uma atividade de tradição e relevância econômica no Rio Grande do Sul, estado mais meridional do Brasil, e no seu país fronteiriço, o Uruguai, dependente da produção e industrialização de carne bovina, carne ovina e lã para o crescimento de sua economia (RIBEIRO, 2003). Durante o século XX, os setores ovinos gaúcho e uruguaio foram afetados por períodos de progressos e crises, que modificaram as estratégias e a dinâmica do agronegócio da ovinocultura. Na perspectiva de consumo, segundo a FAO (2005), a demanda de carne ovina nos países em desenvolvimento vem sendo impulsionada pelo crescimento demográfico, pela urbanização e pelas variações das preferências e dos hábitos alimentares dos consumidores. Assim, o desenvolvimento da produção ovina dos dois países pode ser capaz de atender o consumo mundial crescente, gerando divisas e fortalecendo as cadeias produtivas locais. Ainda, justifica-se o estudo da ovinocultura pela sua característica social de fixação e subsistência de famílias no espaço agrário, contribuindo para o desenvolvimento de áreas rurais.

A transformação do mercado ovino no Brasil e Uruguai, seus desequilíbrios e suas mudanças econômicas, institucionais e produtivas nas últimas décadas expõem uma rica realidade empírica para uma análise econômica heterodoxa. Assim, o arcabouço teórico da Economia Evolucionária surge como alternativa aos modelos analíticos dominantes da área da economia e comercialização agrícola. Contemplando estes pressupostos, a teoria econômica evolucionária caracteriza-se por uma abordagem histórica e possibilita o estudo das estatísticas comparativas, o estudo da mudança, do avanço criativo e de processos ao longo do tempo (DUGGER, 1990).

Nesta perspectiva, o artigo busca confirmar o argumento da Economia Evolucionária de que a mudança tem um papel central na configuração dos mercados e que as firmas não são inerentemente maximizadoras, mas influenciadas por instituições. A partir desta reflexão, as variáveis institucionais e evolucionárias são determinantes no aumento da produção de ovinos no Brasil e no Uruguai?

A fim de implementar esta abordagem teórica e empírica, a pesquisa teve por objetivo analisar e comparar a configuração da ovinocultura no Brasil e no Uruguai sob uma perspectiva evolucionária e estimar a probabilidade de aumento futuro da produção ovina em função de variáveis institucionais e econômicas.

A hipótese central a ser testada é de que a retenção/adaptação das firmas ovinocultoras após um cenário de desequilíbrio e a probabilidade futura de aumento da produção seja influenciada, fundamentalmente, pelo estabelecimento de instituições, como hábitos de pensamento individuais, ações coletivas e regras informais da sociedade. Portanto, a pesquisa buscou realizar uma reflexão sobre a economia agrícola em uma perspectiva evolucionária, usando o caso da ovinocultura no Brasil e Uruguai para confirmar a convergência teórico-empírica.

\section{Economia evolucionária: origem e pressupostos para o estudo da economia agrícola}

A formulação de uma teoria evolutiva, focada na composição das populações, teve início com a recomendação de Charles Darwin como naturalista oficial do navio de pesquisas da Marinha Britânica H.M.S Beagle, que partiu para sua expedição em dezembro de 1831. As observações de Darwin e suas anotações regulares durante a 
expedição foram o alicerce para a reflexão e a formulação de uma teoria evolucionária, consolidada em 1859 com a publicação de "The Origins of Species: by means of natural selection" ${ }^{\prime \prime}$.

Uma década após a publicação da obra de Darwin, muitos acadêmicos cogitaram a utilização dos princípios de variação, herança e seleção para explicar a evolução social, fundamentalmente, por meio das instituições políticas, do aprendizado, do desenvolvimento da ciência e dos princípios éticos, em que as unidades selecionadas não eram os indivíduos, mas a sociedade. Os autores falharam em estabelecer os processos de seleção e replicação de unidades sociais, privilegiando os grupos e as sociedades como um todo (HODGSON, 2005).

No entanto, no mesmo período, o Antigo Institucionalismo emerge, tendo como principais autores Thorstein Veblen, John Commons e Wesley Mitchell, estabelecendo a importância das instituições e proclamando a necessidade de uma economia evolucionária genuína. Seus trabalhos ofereceram diferentes perspectivas sobre a natureza do indivíduo, com base no conceito de hábito, sem a preocupação com uma "teoria do tudo", como na física, mas aproximando-se de uma teoria da mudança, como a biologia evolutiva (HODGSON, 1998). Os seus pressupostos rejeitam a ontologia e o método do liberalismo clássico, expondo severa crítica ao individualismo metodológico (HODGSON, 1993), e postulam a economia como parte de um todo, inserindo o indivíduo em um ambiente de cultura específica (DUGGER, 1990).

Thorstein Veblen foi o principal representante da corrente institucionalista e propunha

3. Para formulação de sua teoria evolutiva, Darwin teve como inspiração os escritos de Malthus. Em sua autobiografia, Darwin (1887, p. 103-104), relata: "depois de haver iniciado minha investigação sistemática, sucedeu-me ler, para me distrair, o texto de Malthus sobre a População [...] Estando bem preparado para apreciar a luta pela vida que se dá por toda parte [...] ocorreu-me prontamente que, naquelas circunstâncias, as variações favoráveis tenderiam a ser preservadas e as desfavoráveis a ser destruídas [...] Desse modo, portanto, eu finalmente havia conseguido uma teoria com que trabalhar". Ainda, em sua obra principal, Darwin (1859) afirma que é na seleção natural que a doutrina de Malthus pode ser aplicada com intensidade. uma formulação teórica do processo da vida econômica em lugar da teoria neoclássica. O indivíduo, aliado ao seu conhecimento, habilidades e hábitos de pensamento, se modifica durante o processo econômico, em contraste ao hedonismo e à natureza humana passiva do neoclassicismo (RUTHERFORD, 1998).

Nesta perspectiva, o indivíduo é determinante na evolução da vida econômica e, para Veblen (1909, p. 626), instituições são "hábitos de pensamento comuns à generalidade dos homens". Os hábitos são consequências dos processos compartilhados por um número de pessoas em uma dada sociedade. Sob um sentido evolucionário, os hábitos e as instituições têm dimensões conectivas (a situação de hoje forma as instituições de amanhã) e são análogas aos genes na biologia. A evolução da estrutura social se consolida como um processo de seleção natural das instituições (HODGSON, 1993).

Quanto mais antigo o hábito, mais legitimado ele se torna; e quanto mais um hábito coincidir com os costumes, mais persistentemente ele se fixará. O hábito será mais firme se as tendências especiais da natureza humana forem tendências já profundamente envolvidas no processo vital, ou intimamente ligadas à história de vida de um determinado grupo (VEBLEN, 1899). Se os hábitos de pensamentos transformam a estrutura social, os indivíduos tornam-se agentes ativos na vida econômica e a direção da sua atividade individual é determinada pelo seu temperamento, hereditariedade, experiência e tradições. No correr da ação, o agente também contribui individualmente para modificar o ambiente no qual está inserido (RUTHERFORD, 1998).

Veblen (1898) construiu uma teoria da mudança e buscou compreender os efeitos do progresso técnico na economia sob um estado estático de equilíbrio e sob um processo evolucionário (HODGSON, 1993).

O Antigo Institucionalismo é comportamental e analisa o comportamento dos indivíduos diante de escolhas. As escolhas são voluntárias ou involuntárias, impostas individualmente ou por princípios de ação coletiva (COMMONS, 1934). O 
institucionalista Commons (1934) empenhou-se em encontrar uma circunstância universal, comum em todo comportamento conhecido como institucional e, então, definiu uma instituição como "uma ação coletiva que controla, libera e amplia a ação individual". No pensamento de Commons (1934), o conceito de instituição forma padrões de conduta, enquanto no pensamento de Veblen (1909), a instituição é mais flexível e libertária.

A obra de John Commons se destaca pela busca de uma organização teórico-metodológica a fim de estimular estudos aplicados às realidades econômicas institucionais. Os legados de seu pensamento foram: a construção de um caráter ontológico institucional, a natureza do ambiente teórico institucionalista; a consolidação de pressupostos teóricos e a busca em formular um método de análise.

Evidencia-se, nas ideias de Veblen (1898) e Commons (1934), o rompimento com a concepção do indivíduo como "dado", maximizador e hedonista, e a formulação de uma teoria institucional que posiciona o indivíduo como o agente da mudança por meio de seus hábitos de pensamento comuns e coletivos. Ainda, o Antigo Institucionalismo crítica o uso de métodos formais, rejeitando a natureza estática e taxonômica da economia neoclássica e afirmando seu desejo de ver a economia como um processo histórico de mudança cumulativa (RUTHERFORD, 1996).

O legado de Veblen e Commons não foi inteiramente positivo, devido ao nível de imprecisão com que as ideias foram determinadas (sobretudo por Veblen), impedindo o desenvolvimento e a aproximação de uma teoria adequada à indústria, à tecnologia e à macroeconomia, restringindo-se a recomendações políticas (HODGSON, 1993).

As ideias veblerianas, para Hodgson (1998), caíram no ostracismo no início do século XX devido às mudanças ocorridas nas ciências sociais a partir da consolidação do método matemático e da filosofia positivista, emergindo novamente a partir da década de 1980 como uma corrente teórica heterodoxa, crítica à economia neoclássica, e formadora de pressupostos fundamentais da economia evolucionária.
Na primeira metade do século XX, após o ostracismo das ideias evolucionárias do Antigo Institucionalismo, Joseph Schumpeter e suas obras trouxeram novamente à tona uma perspectiva evolucionária para a economia. Mesmo que Schumpeter não tenha se declarado um economista evolucionário, fica evidente, mesmo que implicitamente em seu trabalho, a convergência de ideias com o pensamento de Veblen, as quais se tornaram a base para a consolidação de uma economia evolucionária:

todo o conhecimento e todo hábito, uma vez adquirido, incorporam-se firmemente em nós como um terrapleno ferroviário na terra [...]. O campo para a escolha individual sempre estará delimitado pelos hábitos, convenções sociais e coisas semelhantes [...] o estado econômico de um povo não emerge simplesmente das condições econômicas precedentes, mas unicamente da situação total precedente [...] (SCHUMPETER, 1911, p. 44-64). A história da vida econômica do indivíduo é um processo cumulativo de adaptação e mudança contínua, onde tanto o agente como o seu ambiente é resultado do processo passado. Seus métodos de vida são impostos pelos seus hábitos [...]. (VEBLEN, 1898, p. 411).

As contribuições oriundas do Antigo Institucionalismo, de Schumpeter, e das pesquisas em biologia evolutiva não consolidaram por si só uma Teoria Econômica Evolucionária. Houve a necessidade de melhor construção teórica e metodológica a fim de conceber a ontologia desta nova corrente econômica. Neste sentido, a literatura relativa aos processos de inovação (neo schumpeterianos) e a evolução das instituições (neoinstitucionalistas) inspiraram as ideias evolucionárias ${ }^{4}$, e têm demonstrado que a perspectiva

4. A abordagem neoschumpeteriana tem como ponto central o papel da inovação no desenvolvimento econômico. O processo inovativo microeconômico é a porta de entrada das mutações e elemento desencadeador da mudança econômica, em um processo de path dependence (CONCEIÇÃO, 2002). Já os seguidores do Antigo Institucionalismo focam na evolução das convenções e normas sociais, tendo a tecnologia e as instituições como elementos dinâmicos que moldam as decisões individuais 
evolutiva na economia pode fornecer um arcabouço teórico útil para pesquisas aplicadas (DOSI e NELSON, 1994).

O principal marco na incorporação efetiva de argumentos evolucionários no campo da teoria econômica foi a obra An Evolutionary Theory of Economic Change de Richard Nelson e Sidney Winter. A teoria evolucionária proposta por Nelson e Winter (1982) trata as firmas como motivadas pelo lucro, mas não supõem que as suas ações sejam maximizadoras. As conotações mais amplas do termo "evolucionário" incluem uma preocupação com processos de mudança de longo prazo e progressivos. As regularidades observadas na realidade presente não são interpretadas como soluções de um problema estático, mas como resultados produzidos por processos dinâmicos compreensíveis a partir de condições conhecidas ou conjecturadas de forma plausível no passado (NELSON e WINTER, 1982).

As regras de decisão das firmas formam um conceito básico da teoria evolucionária, porém, rejeitando-se a noção de racionalidade ilimitada, otimização das combinações técnicas e o comportamento maximizador a partir do conjunto de escolhas alternativas. Para a teoria evolucionária, os padrões comportamentais regulares e previsíveis das firmas são denominados de "rotinas", que variam de rotinas técnicas a políticas de investimento. As rotinas assumem nos modelos evolucionários a função que os genes apresentam na teoria biológica. As rotinas são características persistentes e determinam, conjuntamente com a influência do ambiente, o possível comportamento do organismo. As rotinas são hereditárias e selecionáveis no sentido de que os organismos de amanhã terão muitas características dos organismos presentes e que organismos com certas rotinas podem sair-se melhor do que outros e, assim, sua importância relativa na população aumenta

(RUTHERFORD, 1996). A aproximação das escolas reside na natureza dinâmica do processo econômico, alicerçado em um aparato institucional, formado por hábitos de pensamento individuais, ações coletivas, rotinas das firmas e tecnologia, que resultam na evolução cumulativa da economia. ao longo do tempo. Entretanto, nem todo o comportamento empresarial seguirá um padrão previsível, regular e, consequentemente, "rotineiro". O comportamento que altera a "rotina" é um fator decisivo na evolução econômica (NELSON e WINTER, 1982).

A influência schumpeteriana reside na força das inovações em romper as rotinas, afetando o desempenho e a estrutura econômica. Para os autores evolucionários, a economia está em constante evolução por saltos cumulativos, mudanças estruturais e processos de seleção/mutação, gerando novos cenários sem um caráter finalístico. Dessa forma, a evolução dos hábitos e instituições e a coevolução com a tecnologia são fatores essenciais para a compreensão da mudança econômica, bem como agenda de pesquisa dos economistas evolucionários ${ }^{5}$. Para Dugger (1990), as características centrais que aproximam estes autores do Antigo Institucionalismo, são: enfatizam o papel do poder na economia; abordam o estudo das instituições; são instrumentalistas e concebem a economia como uma ciência evolutiva.

Os esforços em compreender a evolução das instituições contribuíram para a emergência de uma teoria econômica evolucionária. Hodgson (1992) aponta os principais pressupostos que balizam o pensamento neoinstitucionalista e motivam os economistas a utilizar-se de metáforas evolucionárias no campo econômico: a ideia de um processo de causação cumulativa em oposição às descrições da economia como algo que se desenvolve rumo a uma situação de equilíbrio; a analogia entre o processo de seleção natural dos organismos biológicos e o processo seletivo no mundo social; a diversidade taxonômica da economia por meio da diversidade de indivíduos, de variações, mutações e dinamismos e a necessidade de uma análise evolucionária abranger os

5. Conforme Rutherford (1996), as recentes contribuições institucionais e evolucionárias na economia estão representadas nas páginas do Journal of Economic Issues. Ainda, destacam-se os movimentos realizados pela Association for Institutional Thought (AFIT) e Association for Evolutionary Economics (AFEE). 
três princípios darwinianos de variação, herança e seleção.

Assim, hábitos podem ser moldados ou introduzidos pela cultura, pela prática cotidiana e pela tecnologia, e duram mais que os indivíduos. Ao invés de buscar explicar quem veio primeiro, indivíduos ou instituições, dever-se-ia desvendar os processos que levaram ao desenvolvimento de ambos (HODGSON, 1992, 1998). A convergência entre as escolas do Antigo Institucionalismo e Neoschumpeteriana reside na evolução das instituições e sua influência sobre a mudança tecnológica. Neste contexto, de que forma conceitos evolucionários podem ser usados para compreender as dinâmicas da economia agrícola?

\section{Dinâmica agrícola sob a perspectiva evolucionária: desafios para futuras pesquisas}

A emergência de uma alternativa evolucionária para a compreensão das mudanças na economia agrícola fundamenta-se nas características históricas e biológicas dos setores agrícolas e na identificação de lacunas teóricas na economia neoclássica para elucidar aspectos da dinâmica da agricultura. Uma compreensão neoclássica dos sinais dos mercados agrícolas nem sempre direcionam os indivíduos para decisões mais vantajosas. Isso porque as decisões estão além da alocação ótima de recursos, da maximização dos lucros, da racionalidade ilimitada e do hedonismo. As decisões são muito mais complexas e são influenciadas pelos hábitos de pensamento individuais (VEBLEN, 1899), pela racionalidade limitada, por ações coletivas (COMMONS, 1934), pelos costumes e modos não econômicos de pensar (SCHUMPETER, 1911), pelas regras formais e informais da sociedade (NORTH, 1990) ${ }^{6}$

6. Enquanto o Antigo Institucionalismo rompe definitivamente com pressupostos neoclássicos e proclama uma economia evolucionária, a Nova Economia Institucional (NEI) faz uma crítica à teoria tradicional, mas mantém-se presa ao seu núcleo teórico (LOPES, 2013), sob forte influência neoclássica e austríaca (RUTHERFORD, 1996). A mudança institucional presente na NEI assume predo- e pelo processo de path dependence (NELSON e WINTER, 1982).

Uma reflexão teórica neste campo é o trabalho de Boulding (1981), Agricultural Economics in an Evolutionary Perspective. Para Boulding (1981), as implicações da perspectiva evolucionária na economia agrícola podem ser profundas; a agricultura é um setor da economia que é gerido, inevitavelmente, por um processo biológico que, por sua vez, mantém uma fundamental relação com a evolução social. A agricultura consiste na aplicação de conhecimentos humanos e habilidades a fim de modificar parâmetros dos ecossistemas e, neste sentido, a agricultura deve ser considerada como parte do processo geral de evolução dos ambientes, processo que modificou profundamente, sob uma pressão seletiva, tanto as características dos ecossistemas naturais como da economia agrícola (BOULDING, 1981).

A ortodoxia utilizada no estudo da economia agrícola impede que muitos fenômenos dinâmicos possam ser compreendidos; assim, Boulding (1981) critica o rigor matemático das pesquisas de cunho neoclássico que, para o autor, se transformam em um "rigor mortis" quando se investiga um fato do mundo real com elementos de aleatoriedade e imprevisível mudança. Os modelos matemáticos não deixam de ser importantes, porém, devem ser adaptados aos sistemas que se estão atentos a analisar. A perspectiva evolucionária, para Boulding (1981), representa uma alternativa para o estudo da dinâmica agrícola: "A agricultura é um bom exemplo de um sistema reverberante, onde os ecos não morrem, e compõem um processo em curso de irreversíveis mudanças evolucionárias" (BOULDING, 1981, p. 795).

minantemente conotações neoclássicas, sem ruptura com seus princípios formalísticos, porém, incorpora conceitos da inexistência de ótimo de pareto (CONCEIÇÃO, 2002). Apesar desta ligação, alguns autores da NEI se aproximam das ideias do Antigo Institucionalismo. Para Lopes (2013), as recentes contribuições de Douglass North trazem o conceito de instituições para além de direitos de propriedade e regras formais. North incorpora fatores como a aprendizagem, crenças compartilhadas e sua evolução na explicação da mudança institucional, aproximando-se das ideias de Veblen. 
Por sua vez, uma visão antropológica foi realizada por Bartlett (1987), no estudo Industrial Agriculture in Evolutionary Perspective. Para o autor, apesar de as condições da produção agrícola dos EUA serem determinadas, em grande parte, pelo Estado e aspectos do contexto macroeconômico, as tradições familiares e as diferentes estratégias de exploração agrária desempenham um papel importante na manutenção das atividades e na capacidade de mudança das firmas agrícolas. A visão estabelecida por Bartlett (1987) se aproxima dos conceitos do Antigo Institucionalismo, indicando a importância da presença de hábitos de pensamento e motivações não econômicas na economia agrícola. Ainda, no argumento de Barlett (1987), os mercados agroalimentares são caracterizados pela instabilidade, incerteza e volatilidade, aspectos não só estabelecidos pelo próprio processo de produção agrícola, mas pelas ações da indústria e do estado. Assim, "aspectos da biologia evolucionária darwiniana e bioenergética são úteis na compreensão correta do surgimento e das características da agricultura industrial" (BARTLETT, 1987, p. 138).

Uma reflexão teórico-empírica pioneira sobre o processo de mudança tecnológica na agricultura encontra-se no estudo de Salles Filho (1993). O autor discute a dinâmica de inovação na agricultura e analisa o desenvolvimento da biotecnologia na década de 1990. Salles Filho (1993) destaca que a inovação na agricultura deve ser vista como um processo dinâmico, baseado na origem, difusão e em tipos complexos e interativos de tecnologias. Sua construção teórica parte de um enfoque dinâmico da geração de tecnologia no ambiente agrícola, baseado no pensamento neoschumpeteriano, com forte conotação evolucionária. A tese do autor abriu espaço para estudos aplicados na área, reforçando a necessidade de fortalecer instrumentos teóricos não determinísticos, mas evolutivos, que permitam explicar o processo de inovação na agricultura.

A evolução tecnológica também foi um tema discutido por Possas et al. (1996). Os autores propuseram uma interpretação do processo de inovação tecnológica na agricultura, sob alguns conceitos dinâmicos da economia da inovação fundamentados na abordagem evolucionária. Possas et al. (1996) sugerem uma interpretação em termos de trajetórias de inovação a fim de explicar a complexidade dos regimes tecnológicos na agricultura. O estudo das trajetórias envolve a admissão de que: a) não existe uma trajetória tecnológica na agricultura em que há uma situação tecnológica e competitiva homogênea; b) o conceito de trajetória tecnológica não pode ser tomado como um conceito amplo setorial, mas um conceito relacionado aos mercados dinâmicos competitivos (agrícola ou outros) seguidos pela busca de inovações e mecanismos de seleção; c) deve-se considerar as trajetórias das indústrias relacionadas com a agricultura em suas inter-relações com os mercados agrícolas (POSSAS et al., 1996).

A forma como novas tecnologias são absorvidas pelas firmas foi tema de análise de Cohen e Levinthal (1996). Na visão dos autores, a capacidade de avaliar e utilizar conhecimentos é, em grande parte, uma função do nível de conhecimento relacionado anterior. No nível mais elementar, este conhecimento prévio inclui habilidades básicas ou até mesmo uma linguagem comum, mas também pode incluir o conhecimento das mais recentes descobertas científicas ou tecnológicas em um determinado campo. Assim sendo, o conhecimento prévio confere uma capacidade de reconhecer o valor de novas informações, assimilá-la e aplicá-la para fins econômicos. Essas habilidades constituem, para Cohen e Levinthal (1990, p. 128), o conceito de "capacidade absortiva da firma".

Cohen e Levinthal (1990) argumentam que o desenvolvimento da capacidade absortiva se dá em um processo de path dependence. Nesta lógica, para os autores, a falta de investimento em uma área de especialização pode impedir o desenvolvimento futuro de uma capacidade tecnológica da firma. Nesta perspectiva, o estudo de Cohen e Levinthal (1990) formula um modelo de investimento em pesquisa e desenvolvimento da firma, em que a experiência de P\&D contribui para a evolução da capacidade absortiva das organizações. 
O desenvolvimento das ideias de Cohen e Levinthal (1990), no que tange à acumulação de conhecimento, apresenta caráter evolucionário. Em um ambiente de incerteza, a capacidade absortiva afeta a formação de expectativas, o que permite à firma prever com maior precisão a natureza e o potencial econômico dos avanços tecnológicos. Por sua vez, estas expectativas condicionam o incentivo para investir na acumulação de uma capacidade absortiva posterior. Portanto, as características da capacidade absortiva de cumulatividade e seu efeito sobre a formação de expectativas implicam que seu desenvolvimento está sob o domínio do path dependence (COHEN e LEVINTHAL, 1990).

Em resumo, a premissa básica do conceito de capacidade absortiva é de que a firma precisa de um conhecimento prévio relacionado para assimilar e utilizar novos conhecimentos. Em reflexão, para entender a mudança tecnológica na agricultura, sob a perspectiva de Cohen e Levinthal (1990), é necessário avaliar as habilidades, o aprendizado e o saber-fazer histórico dos produtores rurais. Assim, o nível de apropriação de novas técnicas e conhecimentos dependerá das características desta base "absortiva", resultando na cumulatividade das rotinas das firmas agropecuárias.

Mais recentemente, Vieira Filho et al. (2005) buscaram desenvolver uma visão mais generalizada do processo de evolução da agricultura baseada na economia evolucionária. O referencial teórico utilizado baseou-se nas pressuposições de incertezas do ambiente, na racionalidade limitada dos agentes, no desequilíbrio dinâmico e instabilidade estrutural.

Vieira Filho et al. (2005) apresentam a evolução da produção brasileira de grãos a partir da Taxa Geométrica de Crescimento, comparando, ao longo do tempo, as taxas de produção, produtividade e área colhida. Neste sentido, os autores avaliam o aumento da produção em função da introdução de novas tecnologias (aumento na produtividade) e/ou em função do aumento da área colhida. Posteriormente, Vieira Filho et al. (2005) constroem um Modelo Evolucionário do
Crescimento Agrícola a partir de uma função de produção baseada em uma nova concepção de capital na agricultura. Os resultados dos autores demonstraram que, em um ambiente de competição tecnológica, sobrevivem as cadeias produtivas mais inovadoras em detrimento da marginalização das imitadoras, elevando, assim, as participações de mercado e os lucros de monopólio.

Posteriormente, Vieira Filho e Silveira (2012) realizaram uma revisão crítica da literatura sobre mudança tecnológica, dando destaque à importância das inovações e da absorção de conhecimento para o crescimento agrícola. Quando se busca entender o processo de mudança, deve-se "conciliar a diversidade dos agentes e o caráter dinâmico das inovações, pressupondo instabilidade estrutural, racionalidade limitada e competição tecnológica" (VIEIRA FILHO e SILVEIRA, 2012, p. 735).

Os autores estabelecem uma crítica à visão da agricultura como um setor retardatário no crescimento econômico. Para os autores, a mudança tecnológica na agricultura é um fenômeno amplo que compreende os processos de aprendizagem e de difusão de conhecimento. A indução da tecnologia deve se associar aos elementos schumpeterianos de análise e às mudanças institucionais (VIEIRA FILHO e SILVEIRA, 2012).

Por outro lado, em uma perspectiva de desenvolvimento rural e sustentabilidade, o trabalho de Maréchal et al. (2008) busca discutir como o caráter insustentável dos atuais sistemas de produção agrícolas está diretamente relacionado com a lógica da economia neoclássica e a visão do mundo sobre a ótica cartesiana e newtoniana. Os autores utilizam o exemplo da agricultura do pós-guerra na França para demonstrar a profunda influência da lógica neoclássica sobre a modernização dos sistemas agrícolas, e alegam que os impactos ambientais gerados com a Revolução Verde estão associados com o reducionismo utilizado nas pesquisas em prol do avanço dos setores agrícolas no século XX. Para Maréchal et al. (2008), a perspectiva evolucionária da mudança econômica e sua natureza histórica e de causalidade cumulativa, se tornam adequadas para analisar a dependência e 
a relação das tecnologias com a ampla gama de aspectos culturais, organizacionais e institucionais do ambiente agrícola. Os autores concluem desafiando pesquisadores a verificar como conceitos evolucionários de path dependence e lock-in podem ser aplicados para o desenvolvimento de sistemas agrícolas sustentáveis.

Os trabalhos dos autores citados demonstram diferentes aplicações de conceitos evolucionários em diversos fenômenos empíricos do setor produtivo e industrial. No entanto, a Economia Evolucionária apresenta uma série de novas possibilidades de análise e potencialidades de pesquisas. Na busca por identificar recentes tendências na agenda de pesquisa evolucionária, o trabalho de Witt (2008) demonstrou que as ideias mais significativas desenvolvidas sob a perspectiva econômica evolutiva são: a mudança tecnológica, a criação e uso do conhecimento e a evolução das normas e das instituições. A agenda, baseada no uso de conceitos de conhecimento e a evolução de normas e instituições, indica um potencial campo de pesquisa evolucionária a ser perseguido na análise da economia agrícola.

As discussões teóricas e empíricas e as potencialidades de pesquisa descritas na literatura demonstram uma convergência entre os pressupostos evolucionários e as características do ambiente agrícola. Assim, a partir desta fundamentação, evidencia-se que a economia evolucionária oferece um modelo analítico capaz de auxiliar em pesquisas no ramo da economia agrícola. A forma de utilização da teoria neste artigo pode ser visualizada na Figura 1. O modelo foi resultado da reflexão teórica-institucional e evolucionária, a fim de sintetizar os pressupostos determinantes para a compreensão da dinâmica dos setores agrícolas, destacando as variáveis empíricas e conceitos centrais a serem explorados em um estudo de caso empírico.

$\mathrm{O}$ aspecto central aqui fundamentado, para uma análise evolucionária aplicada à economia agrícola, é o conceito de mudança e seu impacto no comportamento econômico e institucional. A análise da mudança parte de pressupostos teó- ricos chave do Antigo Institucionalismo e da Economia Schumpeteriana. O institucionalismo original contribui com a ideia de que as decisões dos agentes e sua relação com a dinâmica econômica estão atreladas não apenas à alocação ótima dos recursos, à racionalidade e a ações maximizadoras, mas a hábitos de pensamento individuais e ações coletivas, formadores do conceito de instituição da teoria. Estes aspectos podem ser observados empiricamente por meio de variáveis do objeto relacionadas a tipos de motivações, costumes, comportamentos não maximizadores, experiência, hereditariedade de hábitos e convenções, envolvimentos coletivos etc. Por sua vez, a teoria schumpeteriana contribui com a discussão do papel da tecnologia no desenvolvimento econômico, por meio da destruição criativa e sua relação com as rotinas evolucionárias da firma. Estes aspectos podem ser observados empiricamente por meio de variáveis do objeto relacionadas à estrutura das firmas agropecuárias, escolhas produtivas, técnicas de produção, mudança nas rotinas da firma, perfil e nível tecnológico, canais de adoção de tecnologia e inovação agroindustrial.

De forma complementar, as duas correntes econômicas convergem na defesa por uma análise histórica e dinâmica, através do entendimento de processos de causação circular cumulativa de instituições, defendida pelo Antigo Institucionalismo e do conceito de path dependence Neochumpeteriano. Assim, ao invés de focar apenas em uma análise estática e de equilíbrio de mercado, a economia evolucionária oferece pressupostos capazes de estudar a trajetória histórica de determinado fenômeno, a fim de discutir aspectos relativos a mudanças e desequilíbrios, fatores determinantes para compreender a configuração presente dos setores agrários e projetar comportamentos futuros de seus mercados. Portanto, o quadro analítico, por meio das relações construídas, fundamentou o estudo empírico da produção ovina no Brasil e Uruguai, destacando o papel dos aspectos institucionais e econômicos na mudança dos mercados e na perspectiva futura da atividade. 


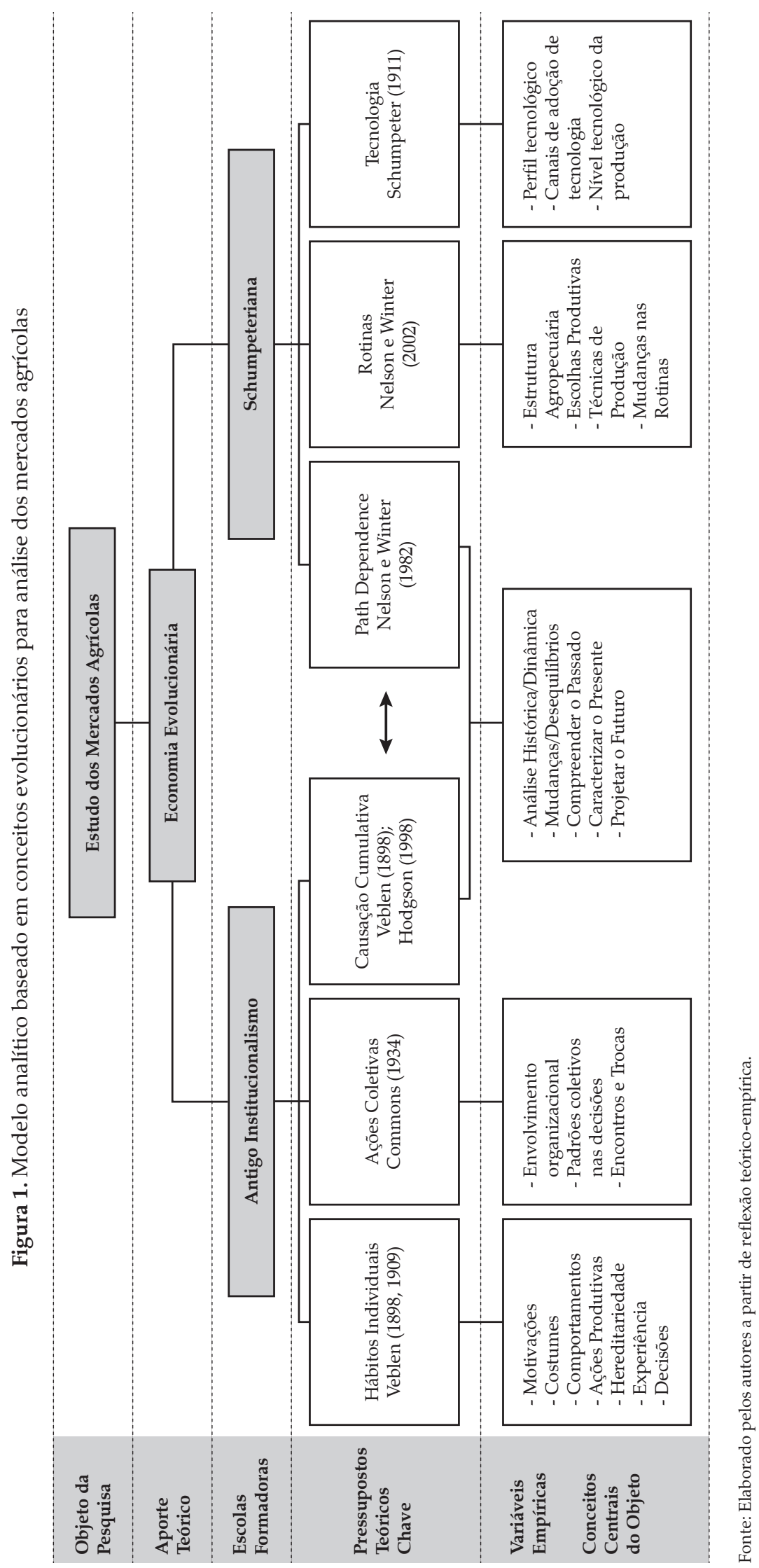




\section{Metodologia de análise do caso empírico}

Para aplicar pressupostos evolucionários na economia agrícola, buscou-se analisar o caso da evolução da ovinocultura Rio Grande do Sul (Brasil) e Uruguai, tendo como referência o modelo analítico previamente desenvolvido. Para tal, foi utilizada uma pesquisa de campo com aplicação de um questionário semiestruturado em uma amostra de ovinocultores a fim de obter a representação da população de firmas ovinas do Rio Grande do Sul e Uruguai. A amostra foi calculada a partir da técnica de "Amostragem para uma estimativa de uma proporção da população". O cálculo resultou em amostra calculada de 94 ovinocultores para o Rio Grande do Sul $(\mathrm{n}=93,21) \mathrm{e}$ 68 ovinocultores no Uruguai $(n=67,25)$. Durante a pesquisa de campo, foi possível estender a aplicação de questionários acima da quantidade amostral, totalizando 120 questionários respondidos no Rio Grande do Sul e 80 no Uruguai. Para manter a representatividade da população, a distribuição de questionários aplicados buscou seguir o nível de concentração da produção ovina nas duas regiões (seleção estratificada).

A aplicação dos questionários foi realizada em diferentes municípios/departamentos do Rio Grande do Sul/Uruguai por meio de contato pessoal com ovinocultores, de encontros/feiras de produtores e da indicação de organizações de apoio ao setor. Para esta pesquisa, o questionário buscou caracterizar:

a) o perfil produtivo/econômico de produtores em termos de: área da propriedade, atividades agropecuárias desenvolvidas, número de animais e raça ovina, produtos ovinos comercializados, manejos nutricionais, reprodutivos e de gestão utilizados, nível tecnológico empregado na ovinocultura, canais de adoção de tecnologias e utilização de instrumentos de crédito.

b) o perfil institucional dos produtores (hábitos, experiência, decisões, motivações etc.) em termos de: tempo em que desenvolve a atividade ovina, se a atividade é herança familiar, as motivações para criar ovinos, o envolvimento com organizações de apoio, projeções da criação ovina para gerações futuras, tomada de decisão, pretensão de produção para o futuro, existência de interação com produtores e perfil socioeconômico do ovinocultor.

c) visão de passado e futuro na identificação do grau de importância ${ }^{7}$ de fatores econômicos e institucionais para: i) o enfrentamento da crise dos preços da lã durante a década de 1990 e permanência do produtor na atividade ovina e ii) o fortalecimento do setor ovino e retenção futura dos produtores na ovinocultura.

Após a pesquisa de campo, os dados foram organizados e tabulados para análise comparativa. Para analisar a retenção da produção ovina no Brasil e Uruguai em um cenário de mudança, foram utilizadas as variáveis de "visão de passado e futuro" na atividade, analisadas por meio de testes de hipóteses paramétricos (Análise de Variância - ANOVA e teste de Tukey).

Para estimar a probabilidade futura de aumento da produção ovina em função de variáveis econômicas e institucionais, utilizou-se a técnica estatística de regressão logística. Os modelos logísticos vêm sendo aplicados em estudos empíricos baseados nos pressupostos da economia evolucionária (FOSTER e WILD, 1999). A regressão logística busca produzir um modelo que permita a predição de valores tomados por uma variável categórica a partir de uma série de variáveis explicativas contínuas e/ou binárias (GUJARATI, 2006).

Assim, foram formuladas duas classes de modelos logísticos: modelo com variáveis inde-

7. O grau de importância de diferentes fatores para o enfrentamento da crise da lã e para o fortalecimento/retenção futura na atividade foi atribuído pelos produtores a partir de uma escala do tipo Likert, segmentada em: nada importante (1), pouco importante (2), indiferente (3), importante (4) e muito importante (5). 
pendentes produtivas/econômicas; e modelo com variáveis independentes institucionais. $\mathrm{O}$ objetivo desta segmentação foi identificar qual perfil (econômico ou institucional) mais impacta no aumento da produção ovina, além de identificar, em cada modelo específico, as variáveis mais relevantes na probabilidade de aumento ou manutenção/diminuição da produção.

Dentro desta perspectiva, foram estimados dois modelos logísticos para cada região analisada (Rio Grande do Sul e Uruguai), sendo denominados de modelo econômico, com variáveis independentes descritas na Tabela 1 e modelo institucional, com variáveis descritas na Tabela 2 .

A estimação do modelo econômico para a ovinocultura do Rio Grande do Sul e Uruguai seguiu o modelo logístico apresentado na equação 1 .

$$
\begin{aligned}
& Y_{i}=\beta_{0}+\beta_{1 \text { AREA }}+\beta_{2 \text { PROD }}+\beta_{\text {3весA }}+\beta_{4 \text { тRоOC }}+ \\
& +\beta_{5 \text { TाEC }}+\beta_{6 \mathrm{GRB}}+\beta_{7 \mathrm{ATV}}+\beta_{8 \mathrm{BR \textrm {ND }}}+\beta_{9 \mathrm{CRED}}+\varepsilon_{\mathrm{i}}
\end{aligned}
$$

Em que: $Y_{i}=$ variável dependente - variáveis dummy $(0,1) ; \beta_{0}=$ intercepto; $\beta \mathbf{i}=$ coeficientes angulares; $\varepsilon_{\mathrm{i}}=$ resíduo.

Tabela 1. Nome, descrição e unidade de análise das variáveis independentes do modelo logístico econômico

\begin{tabular}{|c|c|c|c|}
\hline $\begin{array}{c}\text { Variáveis Econômicas } \\
\text { Independentes }\end{array}$ & $\begin{array}{l}\text { Nome da } \\
\text { Variável }\end{array}$ & Descrição & Unidade de Análise \\
\hline Área da Propriedade & AREA & $\begin{array}{l}\text { Qual a área total (própria e/ou arrendada) da sua } \\
\text { propriedade rural? }\end{array}$ & Valor em hectares \\
\hline Principal Produto & PROD & $\begin{array}{l}\text { Qual é o principal produto de comercialização da } \\
\text { ovinocultura para sua obtenção de renda? }\end{array}$ & $\begin{array}{l}\text { Dummy } \\
0 \text { - Carne Ovina } \\
1 \text { - Lã }\end{array}$ \\
\hline Raça & RAÇA & Qual é a raça ovina criada em sua propriedade? & $\begin{array}{l}\text { Dummy } \\
0 \text { - Duplo Propósito } \\
1 \text { - Raças de Carne } \\
\end{array}$ \\
\hline Troca de raça & TROC & $\begin{array}{l}\text { Você trocou a raça ovina de seu rebanho ou introduziu } \\
\text { uma nova raça em cruzamentos após a crise da lã? }\end{array}$ & $\begin{array}{l}\text { Dummy } \\
0-\text { Não } \\
1-\text { Sim } \\
\end{array}$ \\
\hline Nível de Tecnologia & TEC & $\begin{array}{l}\text { Como você considera o nível de tecnologia aplicado a } \\
\text { sua produção ovina? }\end{array}$ & $\begin{array}{l}\text { Dummy } \\
0 \text { - baixo } \\
1 \text { - médio/alto }\end{array}$ \\
\hline Rebanho & REB & Qual o tamanho de seu rebanho ovino? & Número de cabeças \\
\hline Principal Atividade & ATIV & Qual é a principal atividade econômica da propriedade? & $\begin{array}{l}\text { Dummy } \\
0 \text { - Outra atividade } \\
1 \text { - Ovinocultura } \\
\end{array}$ \\
\hline Renda Não Agrícola & REND & $\begin{array}{l}\text { Apresenta outra fonte de renda além da produção } \\
\text { agropecuária? }\end{array}$ & $\begin{array}{l}\text { Dummy } \\
0-\text { Não } \\
1-\text { Sim } \\
\end{array}$ \\
\hline Utilização de Crédito & CRED & $\begin{array}{l}\text { Utiliza instrumentos de crédito voltados à ovinocul- } \\
\text { tura? }\end{array}$ & $\begin{array}{l}\text { Dummy } \\
0-\text { Não } \\
1-\text { Sim } \\
\end{array}$ \\
\hline $\begin{array}{l}\text { Variável Dependente } \\
\text { Pretensão Futura }\end{array}$ & PRET & Ao projetar o futuro da criação ovina, você pretende: & $\begin{array}{l}\text { Dummy } \\
0 \text { - diminuir/manter a produção } \\
1 \text { - aumentar a produção }\end{array}$ \\
\hline
\end{tabular}
ajustado às amostras do Rio Grande do Sul e Uruguai

Fonte: Elaborado pelos autores. 
Tabela 2. Nome, descrição e unidade de análise das variáveis independentes do modelo logístico institucional ajustado às amostras do Rio Grande do Sul e Uruguai

\begin{tabular}{|c|c|c|c|}
\hline $\begin{array}{c}\text { Variáveis Institucionais } \\
\text { Independentes }\end{array}$ & $\begin{array}{l}\text { Nome da } \\
\text { Variável }\end{array}$ & Descrição & Unidade de Análise \\
\hline Herança Familiar & HER & A criação ovina foi uma herança familiar? & $\begin{array}{l}\text { Dummy } \\
0 \text { - Não } \\
1 \text { - Sim }\end{array}$ \\
\hline Envolvimento Organizacional & ENV & $\begin{array}{l}\text { Como você avalia o seu envolvimento com as } \\
\text { organizações de apoio da ovinocultura? }\end{array}$ & $\begin{array}{l}\text { Dummy } \\
0 \text { - nenhum/baixo } \\
1 \text { - médio/alto } \\
\end{array}$ \\
\hline Próxima Geração & PROX & $\begin{array}{l}\text { Você acredita que a próxima geração de sua famí- } \\
\text { lia continuará desenvolvendo a criação de ovinos? }\end{array}$ & $\begin{array}{l}\text { Dummy } \\
0-\text { Não } \\
1-\text { Sim } \\
\end{array}$ \\
\hline Motivação Tradição Familiar & TRAD & \multirow{4}{*}{$\begin{array}{l}\text { Classifique de } 1 \text { a } 4 \text { as suas motivações para } \\
\text { desenvolver a criação ovina. }\end{array}$} & \multirow{4}{*}{$\begin{array}{l}\text { Medição Intervalar de } 1 \text { (menor } \\
\text { importância) a } 4 \text { (mais importante } \\
\text { motivação) }\end{array}$} \\
\hline Motivação Lucro* & LUCR & & \\
\hline Motivação Subsistência & SUBS & & \\
\hline Motivação Satisfação Pessoal & SATS & & \\
\hline Tempo na Ovinocultura & TEMP & $\begin{array}{l}\text { Há quantos anos a sua propriedade desenvolve a } \\
\text { ovinocultura? }\end{array}$ & Valor em número de anos \\
\hline Idade & IDAD & Qual a sua idade? & Valor em número de anos \\
\hline Mudança de rotinas & ROT & $\begin{array}{l}\text { A crise da lã na década de } 1990 \text { modificou suas } \\
\text { rotinas de produção ovina? }\end{array}$ & $\begin{array}{l}\text { Dummy } \\
0-\text { Não } \\
1-\text { Sim } \\
\end{array}$ \\
\hline $\begin{array}{l}\text { Variável Dependente } \\
\text { Pretensão Futura }\end{array}$ & PRET & $\begin{array}{l}\text { Ao projetar o futuro da criação ovina, você } \\
\text { pretende: }\end{array}$ & $\begin{array}{l}\text { Dummy } \\
0 \text { - diminuir/manter a produção } \\
1 \text { - aumentar a produção }\end{array}$ \\
\hline
\end{tabular}

* Entende-se por "motivação pelo lucro" uma variável institucional ligada à forma de pensar e agir dos produtores, vinculada aos hábitos de pensamento individuais. A motivação não se refere à obtenção de ganho efetivo, mas uma forma de desejo, busca e pretensão, não representando, assim, uma variável estritamente econômica.

Fonte: Elaborado pelos autores.

A estimação do modelo institucional para a ovinocultura do Rio Grande do Sul e Uruguai seguiu o modelo logístico apresentado na equação 2 .

$$
\begin{aligned}
& Y_{i}=\beta_{0}+\beta_{1 \text { HER }}+\beta_{2 \mathrm{ENV}}+\beta_{\text {3РROX }}+\beta_{4 \text { tTRAD }}+\beta_{5 \text { LUCR }}+ \\
& +\beta_{6 \mathrm{SUSS}}+\beta_{7_{\mathrm{SAT}}}+\beta_{8_{\mathrm{TTMP}}}+\beta_{9_{\mathrm{DND}}}+\beta_{10_{\mathrm{ROT}}}+\varepsilon_{\mathrm{i}}
\end{aligned}
$$

Em que: $Y_{i}=$ variável dependente - variável dummy $(0,1) ; \beta_{0}=$ intercepto; $\beta \mathrm{i}=$ coeficientes angulares; $\varepsilon_{\mathrm{i}}=$ resíduo.

Para a estimação dos parâmetros da regressão logística, por não apresentar natureza linear, utilizou-se do Método de Máxima Verossimilhança, ajustando os dados à curva logística em formato "S" (GUJARATI, 2006). As hipóteses testadas pelo teste do Qui-Quadrado $\left(\chi^{2}\right)$, a um nível de $5 \%$ de significância, foram:

a) Hipótese Nula $\left(\mathrm{H}_{0}\right)$ : não há influência das variáveis independentes (econômicas e/ ou institucionais) sobre a variável depen- dente (pretensão de aumento da produção ovina).

b) Hipótese Alternativa $\left(\mathrm{H}_{1}\right)$ : há influência de pelo menos uma variável independente (econômica e/ou institucional) sobre a variável dependente (pretensão de aumento da produção ovina).

O nível de explicação dos modelos foi observado pelo $\mathrm{R}^{2}$ de Nagelkerke, valores que variam de 0 a 1 . Para avaliar quais variáveis independentes afetam, e com que intensidade, a probabilidade dos ovinocultores em aumentar a produção, analisou-se a significância dos parâmetros (betas) por meio do Teste de Wald, ou estatística W, a um nível máximo de $5 \%$ de significância.

Os coeficientes angulares estimados no modelo medem as variações na proporção das probabilidades, ou seja, a razão das desigualdades expressas em logaritmo $(\ln \Delta \mathrm{Y} / \Delta \mathrm{X})$. Para interpretação, utilizou-se a estatística exponen- 
cial do coeficiente angular, denominada de odds ratio. No entanto, para se estimar a probabilidade de um evento ocorrer, ou seja, aumentar a produção, em função do conjunto de variáveis independentes significativas pela estatística $\mathrm{W}$, foi realizada a transformação logit, conforme a equação 3 (GUJARATI, 2006):

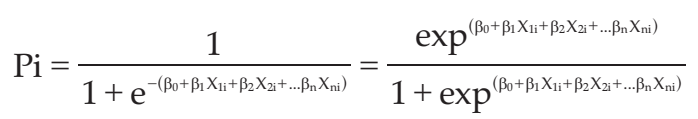

Em que: $\mathrm{P}_{\mathrm{i}}=$ probabilidade do evento ocorrer; e $-\left(\beta_{0}+\beta_{1} X_{11}+\beta_{2} X_{2}+\ldots \beta_{n} X_{n i}\right)=$ exponencial da equação logística negativa.

A função logit possibilita uma série de simulações com as diferentes variáveis econômicas e institucionais significativas. A probabilidade de os produtores aumentarem a produção ovina foi simulada a partir da identificação das variáveis que mais impactam a variável dependente, a partir da construção de cenários. Assim, com a transformação logit, o valor $P_{\mathrm{i}}$ é a estimativa da probabilidade de que um ovinocultor do Rio Grande do Sul ou Uruguai tenha sucesso futuro no aumento da produção ovina. Portanto, buscou-se, com a estimação logística e a transformação logit, avaliar e comparar o grau de dependência e probabilidade do aumento da produção ovina em função de variáveis econômicas e institucionais de produtores das duas regiões.

\section{Resultados e discussão}

\subsection{Instituições e as mudanças no mercado da ovinocultura do Brasil e Uruguai}

O Rio Grande do Sul (Brasil) e o Uruguai são regiões caracterizadas por apresentar fatores culturais, econômicos, ambientais e políticos muito similares. Ao longo das décadas de 1950 e 1960, a ovinocultura era a maior riqueza existente nos campos da fronteira entre as duas regiões; o parâmetro do grau de riqueza de um produtor era dado pelo número de ovelhas que compunham seu rebanho. A lã sustentava todas as necessidades das fazendas, e a fibra passou a ser chamada de "ouro branco". As décadas de 1970 e 1980 foram marcadas pela maior intervenção governamental na agricultura de grãos por meio de diversos instrumentos que vinham com a finalidade de aumentar a produtividade da terra e a oferta de alimentos. Assim, as áreas destinadas à ovinocultura começaram a dar espaço para as lavouras, destacando o crescimento da área plantada dos cultivos de arroz e soja em todo o Rio Grande do Sul (BOFILL, 1996).

O início dos desequilíbrios nos mercados da ovinocultura e das transformações produtivas que afetaram a atividade após 1990 no Rio Grande do Sul e Uruguai teve origem em comportamentos econômicos de agentes do setor laneiro da Austrália. A estratégia australiana de auferir elevados lucros com o aumento dos preços da lã no mercado internacional estimulou o deslocamento da demanda por lã para outras fibras têxteis. Assim, instaurou-se a crise internacional da lã durante a década de 1990, determinando o principal evento negativo da atividade.

Estas mudanças estruturais e conjunturais desestruturaram o setor ovino no Rio Grande do Sul e Uruguai. Muitos produtores desistiram da atividade e o rebanho ovino declinou de forma significativa. Grande parcela das áreas antes destinadas à ovinocultura foi tomada pela bovinocultura de corte e pela agricultura de grãos, e a produção ovina restante tornou-se uma atividade agropecuária secundária, direcionada para subsistência. Paralelamente à crise do setor laneiro, a carne ovina despontava como uma alternativa mercadológica de produção. Todo este processo resultou em mudanças drásticas na economia agrícola das duas regiões, modificando o perfil e o objetivo do setor produtivo ovino.

Em um novo ambiente produtivo, os mercados da ovinocultura apresentaram crescente valorização no final da década de 2000. Os preços pagos ao produtor de carne ovina alcançaram, em 2010, patamares recordes, apresentando "supervalorização" frente aos preços das carnes bovina, suína e de frango. Naturalmente, sob uma perspectiva neoclássica, a motivação de uma firma ou indivíduo, produtor e ofertante de um 
bem valorizado no mercado, estaria relacionada, fundamentalmente, com as vantagens econômicas oriundas deste cenário de valorização, ou seja, com a maximização dos lucros a partir de sua racionalidade ilimitada.

No entanto, mesmo frente a esta "supervalorização", os resultados encontrados na pesquisa de campo indicam que a motivação dos ovinocultores do Rio Grande do Sul e Uruguai não se fundamenta apenas na maximização dos ganhos da atividade, mas também, em mesmo grau, em características institucionais das firmas e dos indivíduos inseridos na ovinocultura. Os tipos de motivação e o seu grau de importância no desenvolvimento da ovinocultura do Rio Grande do Sul e Uruguai podem ser visualizados na Tabela 3.

Constata-se que, no Rio Grande do Sul, a satisfação pessoal foi apontada, a partir da análise dos valores absolutos de importância, como a principal motivação dos produtores para a criação ovina. Porém, cabe destacar que não se evidenciou diferença significativa dos graus de importância entre as motivações de satisfação pessoal e lucro na atividade. Estes resultados confirmam que aspectos institucionais de um ambiente produtivo apresentam a mesma importância do que aspectos econômicos na motivação e direcionamento da atividade ovina.

No Uruguai, a motivação baseada no lucro foi identificada como de maior importância em valores absolutos médios. No entanto, ressalta-se que motivação pelo lucro representa um desejo, uma busca, não necessariamente um ato de maximização. Destaca-se, ainda, a presença de motivações com origem na tradição familiar, outro aspecto institucional importante no estímulo à atividade econômica.

Adicionalmente, a paridade de importância dos aspectos institucionais e econômicos na motivação dos ovinocultores e a relação de hábitos de pensamento individuais, por meio de satisfação pessoal, costumes e tradições, com o direcionamento da atividade ovina, ganham ainda mais destaque frente a um período de "supervalorização" econômica da ovinocultura.

O ambiente atual de valorização dos produtos da ovinocultura contrasta com o período de grave crise ocorrido na década de 1990. Neste sentido, cabe analisar quais fatores econômicos e institucionais foram determinantes para a retenção dos produtores e a adaptação dos sistemas produtivos às novas características de mercado. Assim, a Tabela 4 apresenta as médias dos graus de importância atribuídos pelos produtores de ovinos do Rio Grande do Sul e Uruguai a diferentes fatores econômicos e institucionais no enfrentamento da crise dos preços da lã na década de 1990 por parte de produtores rurais.

$\mathrm{O}$ fator que apresentou maior grau absoluto de importância para o enfrentamento da crise da lã e manutenção na atividade ovina nos anos subsequentes no Rio Grande do Sul e Uruguai foi a tradição existente da firma na ovinocultura e a satisfação pessoal que o produtor obtém com o desenvolvimento da atividade. O resultado encontrado demonstra que fatores institucionais foram determinantes na manutenção de ovinocultores após a mudança estrutural, apon-

Tabela 3. Tipos de motivação e seu grau de importância* no desenvolvimento da ovinocultura nas propriedades pesquisadas do Rio Grande do Sul e Uruguai

\begin{tabular}{lclc}
\hline \multicolumn{1}{c}{ Motivação** $^{*}$} & Rio Grande do Sul & \multicolumn{1}{c}{ Motivação** $^{* *}$} & Uruguai \\
\hline Satisfação Pessoal & $2,88^{\mathrm{a}}$ & Lucro & $3,15^{\mathrm{a}}$ \\
Lucro & $2,85^{\mathrm{a}}$ & Satisfação Pessoal & $2,80^{\mathrm{ab}}$ \\
Subsistência & $2,64^{\mathrm{ab}}$ & Subsistência & $2,44^{\mathrm{bc}}$ \\
Tradição Familiar & $2,19^{\mathrm{b}}$ & Tradição Familiar & $2,09^{\mathrm{c}}$ \\
\hline
\end{tabular}

* Escala de importância varia de 1 a 4, em que 4 representa a mais importante motivação e 1, a de menor importância.

** Médias das atribuições com letras diferentes indicam diferença significativa entre motivações $(p<0,01)$ - dentro das regiões - a partir do Teste de Tukey.

Fonte: Elaborado pelos autores com base em dados primários da pesquisa. 
Tabela 4. Grau de importância* atribuído pelos ovinocultores a diferentes fatores para o enfrentamento da crise da lã e mantença na atividade ovina nos anos subsequentes

\begin{tabular}{|c|c|c|c|}
\hline Fator de Enfrentamento ${ }^{* *}$ & Rio Grande do Sul & Fator de Enfrentamento ${ }^{* *}$ & Uruguai \\
\hline Tradição/Satisfação Pessoal & $4,09^{a}$ & Tradição/Satisfação Pessoal & $3,92^{a}$ \\
\hline Possibilidade de Consumo & $3,88^{\mathrm{ab}}$ & Busca pelo Lucro & $3,90^{\mathrm{a}}$ \\
\hline Características da Propriedade & $3,85^{\mathrm{ab}}$ & Aumento da Demanda & $3,88^{\mathrm{a}}$ \\
\hline Busca pelo Lucro & $3,77^{\mathrm{ab}}$ & Características da Propriedade & $3,79^{\mathrm{a}}$ \\
\hline Aumento da Demanda & $3,57^{\mathrm{ab}}$ & Possibilidade de Consumo & $3,62^{\mathrm{a}}$ \\
\hline Geração/Difusão Tecnologia & $3,45^{\mathrm{b}}$ & Geração/Difusão Tecnologia & $3,36^{\mathrm{a}}$ \\
\hline Apoio de Organizações & $2,40^{c}$ & Apoio de Organizações & $2,54^{\mathrm{b}}$ \\
\hline
\end{tabular}

"Escala do tipo Likert de 5 pontos (1 a 5), sendo que 1 refere-se a "nada importante" e 5, a "muito importante"

"Médias com letras diferentes indicam diferença significativa entre os fatores $(\mathrm{p}<0,01)$ - dentro das regiões - a partir do Teste de Tukey.

Fonte: Elaborado pelos autores com base em dados primários da pesquisa.

tando papel decisivo para as regras informais da sociedade (costumes, tradições etc.) (NORTH, 1990) e modos não econômicos de pensar (SCHUMPETER, 1911) na retenção de produtores após períodos de desequilíbrios e mudanças.

Após uma visão de passado, cabe analisar a importância de diferentes fatores econômicos e institucionais (Tabela 5) no fortalecimento do setor para as próximas décadas e consequente retenção futura dos produtores na atividade ovina (visão de futuro).

Na visão dos produtores do Rio Grande do Sul, os principais fatores elencados para o fortalecimento futuro da atividade ovina são: estimular a demanda pelos produtos ovinos, investir em processamento e industrialização da carne ovina e a necessidade de entidades ligadas ao setor serem mais representativas e atuantes. Nota-se que os principais fatores estão ligados a aspectos econômicos, em que a única diferença estatística na atribuição de importância $(p<0,01)$ foi encontrada entre as médias de "estimular a demanda" e "estimular associativismos".

No caso uruguaio, os produtores inseriram entre os principais fatores para retenção futura na atividade ovina o fator de "incentivar jovens produtores e a paixão pela ovinocultura". Evidencia-se que, para a amostra uruguaia, fortalecer valores pessoais voltados à satisfação, costumes e estimular novas gerações, características de ordem institucional, também são determinantes em uma visão de futuro da atividade.

Sob um aspecto geral dos resultados discutidos, observa-se um comportamento similar no Rio Grande do Sul e Uruguai quanto à trajetória de mudança e as motivações dos ovinocultores. De acordo com Neto (2004), a ovinocultura só avançará em termos produtivos e mercadológicos se os produtores estiverem aptos e cientes da necessidade de mudar. Assim, como discutido teorica-

Tabela 5. Grau de importância* atribuído pelos ovinocultores a diferentes fatores para o fortalecimento do setor e retenção futura na atividade ovina

\begin{tabular}{|c|c|c|c|}
\hline Fator de Fortalecimento** & Rio Grande do Sul & Fator de Fortalecimento** & Uruguai \\
\hline Estimular a demanda & $4,47^{\mathrm{a}}$ & Incentivar jovens/paixão & $4,34^{\mathrm{a}}$ \\
\hline Investimento processamento & $4,31^{\mathrm{ab}}$ & Estimular a demanda & $4,24^{\mathrm{a}}$ \\
\hline Entidades mais atuantes & $4,31^{\mathrm{ab}}$ & Entidades mais atuantes & $4,23^{a}$ \\
\hline Aumentar a produção & $4,23^{\mathrm{ab}}$ & Aumentar a produção & $4,20^{\mathrm{ab}}$ \\
\hline Incentivar jovens/paixão & $4,11^{\mathrm{ab}}$ & Geração/Difusão tecnologia & $4,08^{\mathrm{ab}}$ \\
\hline Geração/Difusão tecnologia & $4,09^{\mathrm{ab}}$ & Investimento processamento & $3,97^{\mathrm{ab}}$ \\
\hline Estimular associativismos & $4,03^{\mathrm{b}}$ & Estimular associativismos & $3,71^{b}$ \\
\hline
\end{tabular}

* Escala do tipo Likert de 5 pontos (1 a 5), sendo que 1 refere-se a "nada importante" e 5, a "muito importante"

** Médias com letras diferentes indicam diferença significativa entre os fatores $(\mathrm{p}<0,01)$ - dentro das regiões - a partir do Teste de Tukey.

Fonte: Elaborado pelos autores com base em dados primários da pesquisa. 
mente e observado nos dados empíricos, mudar refere-se a instituir novos hábitos e rotinas de produção, atentos aos deslocamentos das demandas e oportunidades, adaptando-se aos desequilíbrios inerentes ao movimento econômico não teleológico. Assim, identifica-se que as motivações dos indivíduos e os fatores determinantes na dinâmica dos mercados da ovinocultura nem sempre são influenciados apenas por sinalizações econômicas e produtivas, mas também por motivações e fatores de ordem não econômica, de caráter institucional, baseadas em hábitos de pensamento individuais (VEBLEN, 1898), regras informais - tradição, costumes, além de comportamentos e ações coletivas (COMMONS, 1934). Por conseguinte, a análise indica a aderência da abordagem teórica da economia evolucionária às características da evolução do caso empírico, mais especificamente a utilização de pressupostos de origem no Antigo Institucionalismo na compreensão das mudanças e motivações inerentes a atividade ovina.

\subsection{Probabilidade de aumento da produção ovina: importância de fatores institucionais na retenção produtiva}

As abordagens tradicionais de estudo da economia agrícola destacam a importância de variáveis econômicas, como área, produtividade, tecnologia, crédito etc., na projeção futura de aumento da produção agropecuária. Por outro lado, abordagens heterodoxas, com influência do Antigo Institucionalismo e de conceitos evolucionários da firma, destacariam, adicionalmente, a importância de variáveis institucionais, como motivações, costumes, hereditariedade, envolvimento coletivo etc. nas características das firmas e aumento da produção.

Neste contexto, a análise da influência destas variáveis sob o aumento da produção ovina foi realizada por meio da construção e estimação de duas classes de modelos de regressão logísticos: modelo econômico e modelo institucional. A Tabela 6 apresenta os resultados da estimação logística para aumento da produção ovina no Rio Grande do Sul e Uruguai em função de variáveis econômicas da ovinocultura. Verifica-se que a estatística Qui-Quadrado $\left(\chi^{2}\right)$ do modelo econômico ajustado não foi significativa no Rio Grande do Sul e Uruguai, a um nível estabelecido de significância de 5\%. Este resultado indica a aceitação da hipótese nula, ou seja, não há influência das variáveis independentes econômicas dos ovinocultores, tanto do Rio Grande do Sul como do Uruguai, sobre a variável dependente binária de pretensão de diminuição/manutenção ou aumento da produção ovina.

Destaca-se, associado à estatística Qui-Quadrado, o baixo poder explicativo do modelo

Tabela 6. Parâmetros da regressão logística ajustada às variáveis econômicas da ovinocultura do Rio Grande do Sul e Uruguai

\begin{tabular}{ccccccccc}
\hline \multirow{2}{*}{ Variável } & \multicolumn{3}{c}{ Rio Grande do Sul } & \multicolumn{3}{c}{ Uruguai } \\
\cline { 2 - 9 } & Coeficiente & Wald & Valor $p$ & Exp $(\beta)$ & Coeficiente & Wald & Valor $p$ & Exp $(\beta)$ \\
\hline AREA & 0,000 & 0,448 & 0,503 & 1,000 & 0,000 & 0,002 & 0,965 & 1,000 \\
PROD & $-0,902$ & 2,617 & 0,106 & 0,406 & $-0,130$ & 0,030 & 0,863 & 0,878 \\
RAÇA & 1,126 & 2,869 & 0,090 & 3,082 & 1,188 & 1,334 & 0,248 & 3,282 \\
TROC & $-0,803$ & 1,637 & 0,201 & 0,448 & $-0,113$ & 0,018 & 0,894 & 0,894 \\
TEC & 0,156 & 0,067 & 0,795 & 1,169 & $-0,768$ & 0,994 & 0,319 & 0,464 \\
REB & 0,001 & 1,088 & 0,297 & 1,001 & 0,000 & 0,580 & 0,446 & 1,000 \\
ATIV & 1,364 & 1,833 & 0,176 & 3,914 & $-0,216$ & 0,040 & 0,841 & 0,806 \\
REND & 0,369 & 0,441 & 0,506 & 1,447 & $-0,556$ & 0,528 & 0,467 & 0,574 \\
CRED & $-0,291$ & 0,946 & 0,331 & 0,747 & 0,433 & 0,144 & 0,704 & 1,541 \\
\hline$\beta_{0}$ & $-0,274$ & 0,727 & 0,142 & 0,707 & $-0,053$ & 0,003 & 0,957 & 0,948 \\
$\chi^{2}$ & 10,435 & & 0,316 & & 6,509 & & 0,688 \\
R $^{2}$ Nagelkerke & 0,183 & & & & 0,192 & & \\
\hline
\end{tabular}

Fonte: Elaborado pelos autores a parir das estimações logísticas. 
econômico, visualizado pelo reduzido valor percentual do $\mathrm{R}^{2}$ de Nagelkerke de $18,3 \%$ para a estimação do Rio Grande do Sul e 19,2\% para o Uruguai. Isto demonstra que as variáveis econômicas apresentam reduzida importância na explicação da pretensão futura dos ovinocultores. Consequentemente, de forma individual, não foi constatada nenhuma significância nos coeficientes angulares das variáveis econômicas independentes. Assim, a partir da estimação do modelo logístico econômico, evidencia-se que as variáveis estritamente produtivas e de ordem econômica, como área, existência de renda não agrícola, nível de tecnologia, utilização de crédito, rebanho etc., não se relacionam significativamente $(\mathrm{p}<0,05)$ com a pretensão de aumento da produção ovina no Rio Grande do Sul e Uruguai. Portanto, verifica-se que abordagens teóricas que dão atenção apenas à influência de variáveis econômicas na dinâmica agrícola podem apresentar limitações de análise, como se observa, especificamente, no modelo de projeção futura da ovinocultura.

Por sua vez, a Tabela 7 apresenta os resultados da estimação logística para aumento da produção ovina no Rio Grande do Sul e Uruguai em função de variáveis institucionais da ovinocultura. Constata-se, com base no teste Qui-Quadrado $\left(\chi^{2}\right)$, que os modelos institucionais ajustados aos dados da ovinocultura do Rio Grande do Sul e Uruguai apresentaram significância estatística ( $p$ $<0,01)$.

Ao contrário dos modelos econômicos das duas regiões, a significâncias dos modelos institucionais indicam a aceitação da hipótese alternativa preestabelecida, ou seja, há influência de pelo menos uma variável independente institucional dos ovinocultores, tanto do Rio Grande do Sul como do Uruguai, sobre a variável dependente binária de pretensão de aumento da produção ovina.

Cabe salientar o maior poder explicativo dos modelos institucionais, em comparação com os modelos econômicos, visualizado pelo valor percentual do $\mathrm{R}^{2}$ de Nagelkerke de 38,7\% para a estimação do Rio Grande do Sul e 60,0\% para o Uruguai. Apesar de os valores não alcançarem uma explicação superior, as estimações destes modelos demonstram que a explicação da pretensão futura dos ovinocultores passa por variáveis de ordem institucional, determinando, assim, maior importância destas variáveis para o aumento da produção em comparação com as variáveis de ordem econômica.

Ao analisar individualmente as variáveis institucionais independentes, constatam-se dois coeficientes angulares significativos em cada

Tabela 7. Parâmetros da regressão logística ajustada às variáveis institucionais da ovinocultura do Rio Grande do Sul e Uruguai

\begin{tabular}{ccccccccc}
\hline \multirow{2}{*}{ Variável } & \multicolumn{3}{c}{ Rio Grande do Sul } & \multicolumn{3}{c}{ Uruguai } \\
\cline { 2 - 9 } & Coeficiente & Wald & Valor $p$ & Exp $(\beta)$ & Coeficiente & Wald & Valor $p$ & Exp $(\beta)$ \\
\hline HER & $-0,606$ & 0,770 & 0,380 & 0,546 & $-0,609$ & 0,309 & 0,578 & 0,544 \\
ENV & 1,954 & 11,009 & 0,001 & 7,056 & 0,546 & 0,367 & 0,545 & 1,726 \\
PROX & 0,784 & 1,159 & 0,282 & 2,191 & 0,577 & 0,234 & 0,628 & 1,781 \\
TRAD & 0,289 & 0,969 & 0,325 & 1,335 & 0,423 & 0,873 & 0,350 & 1,526 \\
LUCR & 0,713 & 5,260 & 0,022 & 2,040 & 1,508 & 6,237 & 0,013 & 4,520 \\
SUBS & 0,154 & 0,287 & 0,592 & 1,166 & $-0,319$ & 0,507 & 0,476 & 0,727 \\
SATS & 0,365 & 1,362 & 0,243 & 1,440 & 0,528 & 1,300 & 0,254 & 1,696 \\
TEMP & 0,005 & 0,235 & 0,628 & 1,005 & 0,005 & 0,080 & 0,778 & 1,005 \\
IDAD & $-0,27$ & 2,430 & 0,119 & 0,974 & $-0,077$ & 4,500 & 0,034 & 0,925 \\
ROT & 0,316 & 0,341 & 0,560 & 1,372 & 0,277 & 0,120 & 0,729 & 1,319 \\
\hline$\beta_{0}$ & $-3,850$ & 2,019 & 0,155 & 0,021 & $-2,740$ & 0,447 & 0,504 & 0,065 \\
$\chi^{2}$ & 32,571 & & 0,000 & & 37,540 & & 0,000 & \\
$\mathrm{R}^{2}$ Nagelkerke & 0,387 & & & & 0,60 & & \\
\hline
\end{tabular}

Fonte: Elaborado pelos autores a parir das estimações logísticas. 
região, verificados pelo Teste de Wald a um nível máximo de 5\% de significância. No Rio Grande do Sul, as variáveis independentes institucionais significativas foram o envolvimento organizacional dos produtores $(\mathrm{p}<0,01)$ e a motivação pelo lucro do ovinocultor $(\mathrm{p}<0,05)$.

Assim, a partir da interpretação da exponencial dos coeficientes angulares significativos do Rio Grande do Sul (odds ratio), verifica-se que os ovinocultores que apresentam um nível médio ou alto de envolvimento com organizações de apoio da cadeia produtiva apresentam 7,05 vezes mais chances de aumentar a produção ovina do que produtores com nenhum ou baixo envolvimento. Sob ponto de vista teórico, o envolvimento dos produtores com organizações de apoio relaciona-se com a formação de ações coletivas que, para Commons (1934), abarcam desde costumes desorganizados até interesses sociais; conceito de instituição que forma padrões de conduta. Da mesma forma, a cada grau de aumento na motivação pelo lucro na atividade, o ovinocultor apresenta chance 2,04 maior de aumentar a produção ovina.

Para a ovinocultura do Uruguai, as variáveis independentes institucionais significativas foram a idade do produtor $(p<0,05)$ e a motivação pelo lucro do ovinocultor $(\mathrm{p}<0,05)$. O resultado exponencial do coeficiente angular significativo da variável motivação pelo lucro indica que a cada grau de aumento desta motivação, o ovinocultor uruguaio apresenta 4,52 vezes mais chance de aumentar a produção ovina.

A idade do produtor é uma variável que demonstra características de experiência, vivência e revitalização da atividade. A partir desta leitura e do sinal negativo do coeficiente angular da variável, infere-se que quanto mais jovem for o produtor, maiores serão as chances do aumento da produção ovina no estabelecimento rural, mantendo-se os demais fatores constantes. Este resultado pode estar relacionando ao receio, resguardo e conservadorismo dos produtores mais experientes, fruto dos efeitos da crise internacional dos preços da lã que modificaram os hábitos individuais dos produtores, gerando posiciona- mentos menos arrojados e com maior aversão ao risco. Este comportamento de conservadorismo atrelado às mudanças do mercado ovino está ligado à visão de Veblen (1899) de que quanto mais antigo o hábito, mais legitimado ele se torna; e quando este hábito coincidir com os costumes, mais persistentemente ele será.

Os produtores mais jovens, por sua vez, estariam menos vinculados aos efeitos da mudança estrutural e mais próximos da adaptação e reestruturação da atividade, não coincidindo hábitos com costumes e gerando novos impulsos por investimentos e, consequentemente, aumento da produção ovina. Esta característica de valorização dos jovens na ovinocultura pode ser encontrada no principal fator de fortalecimento futuro da atividade indicado pelos ovinocultores amostrados no Uruguai e no fomento de associações de jovens produtores.

Na discussão da influência institucional sobre a pretensão futura dos ovinocultores, destaca-se que a variável motivação pelo lucro apresentou-se significativa, tanto no modelo estimado do Rio Grande do Sul como no estimado para o Uruguai. A motivação pelo lucro torna-se uma importante variável explicativa institucional pela sua característica de intenção, estímulo e ação de cunho pessoal. As motivações refletem um modo de pensar, uma forma de instituição, baseada em hábitos de pensamento individuais (VEBLEN, 1898); um comportamento diante de escolhas, que voluntárias ou involuntárias, são impostas individualmente ou por ações coletivas (COMMONS, 1934).

Nesta perspectiva do Antigo Institucionalismo, a motivação pelo lucro, portanto, é uma variável institucional vinculada à forma de pensar e agir dos produtores e influencia positivamente o aumento da produção ovina no Rio Grande do Sul e Uruguai, ao contrário das variáveis econômicas não significativas, as quais não refletem formas de pensar e estímulos individuais. Dessa forma, a motivação pelo lucro não é sinônimo de "maximização dos lucros da firma", pois é determinada por hábitos de pensamentos individuais moldados na cumulatividade das mudanças históricas e não apenas na "alocação 
ótima de recursos escassos". O resultado de motivação encontrado nos modelos vai ao encontro da teoria evolucionária proposta por Nelson e Winter (1982), que trata as firmas como motivadas pelo lucro, mas não supõem que as suas ações sejam maximizadoras.

A Tabela 8 apresenta as probabilidades de sucesso para a ovinocultura do Rio Grande do Sul em função do nível de envolvimento organizacional do produtor e de seu grau de motivação pelo lucro. Visualiza-se que, à medida que cresce o grau de motivação, associado com um médio ou alto envolvimento organizacional, a probabilidade de sucesso no aumento da produção ovina aproxima-se de $100 \%$.

Comparando-se o cenário 1 e 2, verifica-se que, mantendo o grau baixo de motivação constante, um crescimento no nível de envolvimento com organizações de apoio gera a elevação da probabilidade de sucesso no aumento da produção ovina de $67,1 \%$ para 93,51\%. De forma similar, nos cenários 1 e 3, quando mantém-se constante nenhum ou baixo envolvimento organizacional e eleva-se para "alto" o grau de motivação pelo lucro, a probabilidade de sucesso no aumento da produção cresce de $67,1 \%$ para $94,54 \%$. No entanto, comparando-se os cenários 2 e 4, quando o produtor já apresenta um médio ou elevado envolvimento, a elevação do grau de motivação pelo lucro gera apenas um pequeno aumento de 3,68 pontos percentuais na probabilidade de sucesso.

A Tabela 9 apresenta a probabilidade de sucesso dos produtores do Uruguai no aumento da produção ovina em função do grau de motivação pelo lucro e da idade do ovinocultor. Visualiza-se que, à medida que cresce o grau de motivação dos produtores pelo lucro, associado à juventude do ovinocultor, a probabilidade de sucesso no aumento da produção ovina se eleva.

Tabela 8. Probabilidade de sucesso de produtores do Rio Grande do Sul, Brasil, no aumento da produção ovina em diferentes cenários com variáveis institucionais significativas

\begin{tabular}{cccc}
\hline Cenário & Grau de Motivação* & $\begin{array}{c}\text { Envolvimento com } \\
\text { Organizações de Apoio }\end{array}$ & $\begin{array}{c}\text { Probabilidade de Sucesso no } \\
\text { Aumento da Produção Ovina** }\end{array}$ \\
\hline 1 & Baixo & Nenhum/Baixo & $67,10 \%$ \\
2 & Baixo & Médio/Alto & $93,51 \%$ \\
3 & Alto & Nenhum/Baixo & $94,54 \%$ \\
4 & Alto & Médio/Alto & $99,19 \%$ \\
\hline
\end{tabular}

*Grau de importância atribuído pelos ovinocultores do Rio Grande do Sul para a motivação pelo lucro

** Estimação realizada por meio da transformação logit

Fonte: Elaborado pelos autores a parir das estimações logísticas.

Tabela 9. Probabilidade de sucesso de produtores do Uruguai no aumento da produção ovina em diferentes cenários com as variáveis institucionais significativas

\begin{tabular}{cccc}
\hline Cenário & Grau de Motivação* & $\begin{array}{c}\text { Idade do Ovinocultor } \\
\text { (Anos) }\end{array}$ & $\begin{array}{c}\text { Probabilidade de Sucesso no } \\
\text { Aumento da Produção Ovina** }\end{array}$ \\
\hline 1 & Baixo & 70 & $2,02 \%$ \\
2 & Baixo & 50 & $8,77 \%$ \\
3 & Baixo & 30 & $30,96 \%$ \\
4 & Alto & 70 & $65,52 \%$ \\
5 & Alto & 50 & $89,86 \%$ \\
6 & Alto & 30 & $97,64 \%$ \\
\hline
\end{tabular}

*Grau de importância atribuído pelos ovinocultores do Uruguai para a motivação pelo lucro

** Estimação realizada por meio da transformação logit

Fonte: Elaborado pelos autores a parir das estimações logísticas. 
Portanto, sob o ponto de vista econômico e produtivo, infere-se que a pretensão de aumento da produção ovina no Rio Grande do Sul e Uruguai não é influenciada por aspectos de tamanho da propriedade, número de rebanho, acesso a crédito ou principal atividade desenvolvida. $\mathrm{O}$ aumento futuro da produção é influenciado por variáveis institucionais, relacionadas com hábitos de pensamentos e ações coletivas, instituições estabelecidas ao longo de um processo evolucionário de mudanças e desequilíbrios. Assim, compreender a evolução da ovinocultura do Rio Grande do Sul e Uruguai significa romper com a natureza humana passiva do mainstream econômico e reconhecer o indivíduo como determinante na dinâmica da atividade. O caso empírico de análise da produção ovina oferece uma diversidade de elementos que reforçam a importância do uso da abordagem econômica institucional e evolucionária para o estudo de fenômenos da área de economia agrícola.

\section{Conclusões}

A pesquisa possibilitou criar um modelo para explicar e explorar fenômenos empíricos com base na teoria evolucionária, abrindo espaço para uma nova visão sobre os estudos voltados às cadeias agroalimentares. Esta forma de estudar um mercado rural permite explicar o movimento histórico da atividade agropecuária, suas mudanças e suas relações com o presente e o futuro. Ao longo desta trajetória posicionam-se os indivíduos que, percebendo a realidade da economia rural circundante, formam instituições e padrões coletivos de conduta. A partir do caso estudado, sugere-se que as instituições, características das firmas produtoras, atuaram como um mecanismo de seleção, mantendo as variações produtivas e retendo produtores na atividade ovina.

Assim, em uma análise geral à luz dos conceitos apreciados na fundamentação teórica, identifica-se que estudar a trajetória e as mudanças da ovinocultura do Rio Grande do Sul, Brasil, e Uruguai significa romper com a natureza humana passiva do neoclassicismo; os indivíduos que presenciaram a mudança estrutural no setor, ou ingressaram após o período de desequilíbrios do mercado ovino, tornaram-se agentes ativos na vida econômica da atividade, modificando o ambiente no qual estavam inseridos, com comportamentos determinados pelas características produtivas e econômicas inerentes à dinâmica agrícola, mas também por ações influenciadas pela hereditariedade, experiência, tradições e motivações pessoais. Deste modo, ressalta-se a importância das instituições na dinâmica dos mercados agrícolas, tratando o indivíduo como um agente nem sempre maximizador e ativo no processo econômico, em que a compreensão dos mercados só é possível em uma perspectiva de path dependence.

Portanto, o esforço em aproximar conceitos da economia evolucionária ao caso da configuração da produção ovina demonstrou uma rica realidade empírica para a aplicação de seus pressupostos econômicos, buscando, além de compreender este fenômeno, estimular o fortalecimento desta aproximação teórico-empírica em diversos temas da economia agrícola. Os resultados também expõem elementos importantes para o debate sobre políticas públicas para o setor, como a preocupação com aspectos institucionais, a presença de jovens na atividade, o envolvimento organizacional dos produtores e o foco em motivações individuais. Assim, entende-se que enquanto houver regras informais e características institucionais não contempladas por ações de fomento, junto à política creditícia, não haverá um retorno massivo e atendimento pleno dos objetivos públicos para a cadeia produtiva.

Salientam-se como limitações e desafios para próximos estudos a impossibilidade da inclusão na amostra de produtores que já deixaram a atividade, a fim de analisar os fatores que motivaram a substituição da produção; e o baixo ajuste dos modelos econométricos, indicando que outras variáveis não inseridas no modelo poderiam explicar melhor a pretensão futura dos produtores. Destaca-se, ainda, como desafio futuro, a necessidade de melhor análise sobre como dife- 
rentes formas de instituições podem atuar como um mecanismo de seleção nos mercados afetados por desequilíbrios, como ocorrido no caso estudado da ovinocultura. Dessa forma, busca-se em próximas pesquisas verificar a aderência deste mecanismo em outras dinâmicas agropecuárias, a fim de identificar o poder geral das instituições em processos de adaptação e evolução dos mercados rurais.

\section{Referências bibliográficas}

BARLETT, P. F. Agriculture in evolutionary perspective. Cultural Anthropology, v.2, n.1, p. 137-154, 1987.

BOFILL, F. J. A Reestruturação da Ovinocultura Gaúcha. Guaíba: Editora Agropecuária, 1996.

BOULDING, K. E. Agricultural economics in an evolutionary perspective. American Journal of Agricultural Economics, v. 63, n. 5, p. 788-795, 1981.

COHEN, W. M. e LEVINTHAL, D. A. Absorptive capacity: a new perspective on learning and innovation. Administrative Science Quarterly, v. 35, n. 1, p. 128-152, 1990.

COMMONS, J. R. Institutional economics. Madison: University of Wisconsin Press, 1934.

CONCEIÇÃO, O. A. C. Instituições e mudança na ótica institucionalista. Porto Alegre: Fundação de Economia e Estatística (Teses FEE, n.1), 2002.

CRAMER, G. L. et al. Agricultural economics and egribusiness. New York: John Wiley and Sons, 1997.

DARWIN, C. Origem das espécies. Belo Horizonte: Itatiaia, 1985. Original em 1859.

Autobiografia 1809-1882. Rio de Janeiro: Contraponto, 2000. Original em 1887.

DOSI, G. e NELSON, R. R. An introduction to evolutionary theories in economics. Journal of Evolutionary Economics, v. 4, p. 153-172, 1994.

DUGGER, W. The New Institutionalism: new but not institutionalist. Journal of Economic Issues, v. 24, n. 2, p. 423-431, 1990.

FAO. Perspectivas agrícolas 2005-2014. Roma: OCDEFAO, 2005.

FOSTER, J. e WILD, P. Econometric modeling in the presence of evolutionary economics. Cambridge Journal of Economics, v. 23, p. 749-770, 1999.
GUJARATI, D. N. Econometria básica. Rio de Janeiro: Elsevier, 2006.

HODGSON, G. M. Thorstein Veblen and postDarwinian Economics. Cambridge Journal of Economics, v. 16, n. 3, p. 285-301, 1992.

. Institutional economics: surveying the 'old' and the 'new'. Metroeconomica, v. 44, n. 1, p. 1-28, 1993.

. The approach of institutional economics. Journal of Economic Literature, v. 36, p. 166-192, 1998.

. Generalizing Darwinism to social evolution: some early attempts. Journal of Economic Issues, v. 39, n. 4, p. 899-914, 2005.

LOPES, H. C. Instituições e crescimento econômico: os modelos teóricos de Thorstein Veblen e Douglass North. Revista de Economia Política, v. 33, n. 4, p. 619637, 2013.

MARÉCHAL, K. et al. The influence of economics on agricultural systems: an evolutionary and ecological perspective. Université Libre de Bruxelles: Centre Emile Bernheim, Working paper n. 28, 2008.

NELSON, R. R. e WINTER, S. An evolutionary theory of economic change. Cambridge: Harvard University Press, 1982.

NELSON, R. R. e WINTER, S. G. Evolutionary theorizing in economics. The Journal of Economic Perspectives, v. 16, n. 2, p. 23-46, 2002.

NETO, O. A. P. Práticas em ovinocultura: ferramentas para o sucesso. Porto Alegre: SENAR/RS, 2004.

NORTH, D. C. Institutions, institutional change and economic performance. Cambridge: University Press, Cambridge, 1990.

POSSAS, M. L. et al. An evolutionary approach to technological innovation in agriculture: some preliminary remarks. Research Policy, v. 25, p. 933-945, 1996.

RIBEIRO, C. Importância socioeconômica da ovinocultura. In: EMBRAPA. Sistemas de criação de ovinos nos ambientes ecológicos do sul do Rio Grande do Sul. Bagé: EMBRAPA, Sistemas de Produção 2, 2003.

RUTHERFORD, M. Institutions in economics: the old and new institutionalism. New York: Cambridge University Press, 1996.

. Veblen's evolutionary programme: a promise unfulfilled. Cambridge Journal of Economics, v. 22, p. 463477, 1998. 
SALLES FILHO, S. L. M. A dinâmica tecnológica da agricultura: perspectivas da biotecnologia. 1993. 239p. Tese (Doutorado em Teoria Econômica) - Unicamp, Campinas, 1993.

SCHUMPETER, J. A. The theory of economic development: an inquiry into profits, capital, credit, interest, and the business cycle. New York: Rutgers, 2008. Original em 1911.

VEBLEN, T. Why is economics not an evolutionary science?" Cambridge Journal of Economics, v. 22, p. 403414, 1998. Original em 1898.

. The theory of the leisure class. New York: Dover Publications, 1994. Original em 1899.
. The limitations of marginal utility. The Journal of Political Economy, v. 17, n. 9, p. 620-636, 1909.

VIEIRA FILHO, J. E. R. et al. Abordagem alternativa do crescimento agrícola: um modelo de dinâmica evolucionária. Revista Brasileira de Inovação, v. 4, n. 2, p. 425-476, 2005.

VIEIRA FILHO, J. E. R. e SILVEIRA, J. M. F. J. Mudança tecnológica na agricultura: uma revisão crítica da literatura e o papel das economias de aprendizado. Revista de Economia e Sociologia Rural, v. 50, n. 4, p. 717738, 2012.

WITT, U. What is specific about evolutionary economics? Journal of Evolutionary Economics, v. 18, p. 547-575, 2008. 